\title{
Ver y sentir (pantallas). Diseño, dispositivos y emoción
}

\section{Petruska Gatica Ramírez, Pamela}

Resumen:

Este escrito aborda los aspectos que hacen a la experiencia emocional que los distintos diseños audiovisuales generan en base a diferentes estímulos.

Palabras clave:

dispositivos - pantallas - emoción. $\left(^{*}\right)$ Diseñadora en comunicación visual. Doctora en Investigación en diseño, Universidad de Barcelona. Docente Taller de Imagen, Instituto Profesional Santo Tomás - Santiago de Chile.Imágenes en movimiento en la vida cotidiana

Hace poco más de diez años Kevin Roberts, de Saatchi \& Saatchi,

Cuadernos del Centro de Estudios de Diseño y Comunicación Nº 66

\begin{tabular}{|c|c|}
\hline Cuaderno $66=$ & ISSN: 1668-0227 \\
\hline 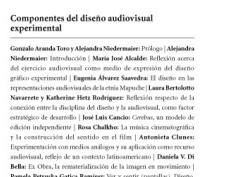 & $\begin{array}{l}\text { Componentes del } \\
\text { diseño audiovisual } \\
\text { experimental }\end{array}$ \\
\hline
\end{tabular}

Año XVIII, Marzo 2018, Buenos Aires, Argentina | 196 páginas

descargar PDF ver índice de la publicación

Ver todos los libros de la publicación

compartir en Facebook

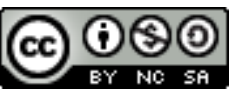
Esta obra está bajo una Licencia Creative Commons Atribución-NoComercialCompartirlgual 4.0 Internacional planteaba que el futuro estaba en las pantallas, la peculiaridad de la imagen en movimiento con sus estímulos sensoriales, el sight, sound and motion1, permitirían crear conexiones emocionales con las personas. Actualmente, en nuestro vivir cotidiano es evidente, y a veces invasiva, la irrupción de las pantallas en las ciudades; lo que nos obliga a detenernos un poco, para la observación e investigación de la experiencia que puedan tenerlas personas en su diario vivir -y convivir- con ellas.

La experiencia sensorial asociada a la visión y el sonido, así como a la apariencia de movimiento, es un estímulo que hipnotiza y suele predominar por encima de los otros aspectos sensoriales. Lo que antes era una situación eventual, dada solamente por la visita al cine, posteriormente sería cotidiana, por la televisión en la casa, y actualmente es de todo momento y en diversos espacios: con el teléfono, el computador personal, el reloj de pulsera, los monitores del metro, el coche, el iPad, etc. Desde el gif animado a la película en 3D (4D incluso). A través de estos dispositivos la corriente estimulante de imágenes en movimiento es arrolladora, nubla la percepción temporal, amplía la idea de comunicación, desarrolla la economía de pensamiento reflexivo, naturaliza el lenguaje como expresión de afectos, etc. Porque ya no sólo se puede ser un mero observador, también se puede interactuar. 
El material audiovisual presente en la cotidianidad está dotado de signos que hemos ido apropiando culturalmente para comprender sus narrativas. Estos múltiples signos, en cantidades incuantificables, deambulan en nuestra cultura de consumo en la que todo pareciera tener que ser difundido mediáticamente (Groys, 2008). Es tan grande que suelen confundirse las diversidades narrativas por el ruido general del exceso de información. El estudio analítico de las narrativas contenidas en los productos audiovisuales (películas o animación)2 permiten observar un "paisaje"a veces cultural otras psicológico, creado por determinados autores, o colectivos, que conforman identidad (como un "espejo") de las diversas realidades culturales en las que se convive (Silva, 2012). Desde el momento en que la reproductibilidad de las imágenes en movimiento se hace masiva, se amplían las posibilidades analíticas y también críticas.

En la cultura del consumo, en la que nos organizamos para consumir y desechar, la lógica se repite para convivir con una constante producción de imágenes que se consumen y van a dar al rincón del olvido, o se pierden en el timeline de las denominadas redes sociales. Los signos en la imagen se arman y rearman para seducir desde las sensorialidad que provoca el ver el movimiento aparente desde un dispositivo luminoso.

Las narrativas que se ofrecen en el contenido de imágenes en movimiento se articulan en las pantallas como interfaces de experiencias sensoriales junto con otros aspectos; entre ellos, la pantalla misma como artefacto.Experiencia, diseño y emoción

Esta "presencia" del dispositivo que media y las imágenes en movimiento se conjugan con la persona y sus afectos. Desde el diseño, esta vinculación con los procesos emocionales presenta un escenario donde las diferentes concepciones de lo que es emocional, (ya sean las cualidades de lo dinámico, de una tendencia a, de una lógica atemporal y/o una predeterminación cultural en la valoración afectiva) se torna relevantes para la cultura, así como para la interacción de las personas y los artefactos de uso cotidianos(además, emoción y movimiento son parientes etimológicos).

En la idea de un diseño para la experiencia, o como experiencia, el diseñador "no simplemente es un creador de objetos, sino un facilitador de experiencias, y esta idea de experiencia es la que debe ser punto de partida y enfoque del diseño"3 .

En el ámbito del diseño vinculado a los afectos se persigue que esta vinculación permita la caracterización y personalización de artefacto (Norman, 2005), siendo esta caracterización y personalización un acercamiento a la persona que hace uso del objeto diseñado; es decir, la función de un artefacto además adquiere una dimensión proyectada en base a los procesos emocionales del usuario.

Cuando esta visión es orientada al consumo, la inclusión del concepto emocional debiera tener particular énfasis en la motivación positiva hacia el artefacto, renombrado como "producto con emoción", emotional product (Jordan, 2002); siendo este producto diseñado para crear una 'experiencia' con él. En esta línea, Peter Desmet4 plantea que dado que la función de la emoción es motivar la conducta adaptativa en respuesta a las circunstancias de una persona, implica que las condiciones desencadenadas pueden involucrar alguna evaluación de la significancia del evento para el bienestar de esa persona. Esta evaluación es a menudo referida como una apreciación o valoración5 no-intelectual ni automática sino más bien consciente y deliberada. 
El diseño vincula a la emoción como esa cualidad vital del hombre, que se genera a través de la experiencia sensorial. Adank y Warrell6 señalan que para el diseño de técnicas basadas en diseño para los sentidos, se han de tener en cuenta tres aspectos: la intimidad, la subjetividad y la temporalidad de la sensación.

Primero, en la intimidad, se tiene en cuenta la proximidad con la que se está frente al producto, artefacto. Por ejemplo, el teléfono móvil posee una cercanía mucho mayor que la luz del tránsito, por usar el mismo ejemplo que los autores, el teléfono involucra el tacto, la visión y el sonido, lo que enriquece significativamente la experiencia. A medida que la experiencia interactiva se mueve de lejos a cerca la experiencia sensorial aumenta, los diferentes estímulos involucran un rango mayor de sentidos. Con este incremento se puede hacer una evaluación más completa e íntima de la interacción del producto.

Segundo, la subjetividad de la sensación tiene que ver con la preferencia personal por un producto mediada por factores internos que tienen que ver con la cultura, la experiencia pasada y el grupo de pares.

Y, por último, el cómo a través del tiempo se da la sensación, nuestra evaluación inicial puede variar por consecuencia de la serie de experiencias sensoriales, lo que posibilita el que no se podamos, transcurrido un tiempo, notar los mismos estímulos porque ya nos acostumbramos a él.

Cuando el diseño, como actividad profesional, introduce y vincula las cualidades de lo emocional al proceso de diseño adquiere un compromiso que lo posibilita reconocer las dimensiones emocionales del entorno y de sus habitantes. Le hace partícipe de su compromiso profesional y responsabilidad social, como planteara Pelta:Estamos rodeados de imágenes construidas por diseñadores y esas imágenes, evidentemente, tienen una influencia en los espectadores, porque originan y sostienen ideas sobre lo que es deseable y normal. Son expresiones culturales creadas para influir en nuestras aspiraciones y alimentar nuestros deseos7 .Por otro lado, cuando el diseñador, como profesional, hace evidente su preocupación por lo emocional, lo afectivo, permite abrir un espacio de empatía que entonces servirá para reconocer las emociones de otros, y también desde ahí las propias emociones.

Teniendo en cuenta que la cultura humana está fundada en el cambio, donde, a decir de Groys: "Todos los procedimientos culturales son procedimientos de cambio y todos los valores culturales son sustituibles (...) no hay valores 'eternos', pues todos los valores, antes o después, son sustituibles"8 .

Es desde este enfoque que la posibilidad de enrolarse en el papel de observador y autoobservador vendría a recuperar el compromiso de crear "soluciones" desde la forma, para la experiencia, entendiendo forma y experiencia como elementos que están en constante cambio, transformaciones que representan parte de cualidades emocionales del ser humano.

Desde esa responsabilidad el diseñador introduce y se halla inmerso en un ámbito que afecta sus decisiones y afecta las formas de su entorno a través de lo diseñado.Representación y experiencia

Se entiende que el individuo occidental existe como actor social en base a su elección de consumo, lo que deviene en una preocupación del diseño para producir objetos que están cada vez más orientados a las necesidades específicas y expectativas de los individuos. Ya que la cultura del consumo pudiera estar asociada 
a la crisis de identidad por la cual, como un loop en pantalla, una continua cadena de imágenes circula sin propósito aparente.

La investigación en diseño se puede orientar al estudio de la experiencia frente a las imágenes en movimiento que acompañan el devenir cotidiano de los usuarios, insertas en los diferentes dispositivos; actuando como un todo en el entorno de las personas, como individuos y como participantes del ritmo de una ciudad.

La investigación vinculada a aspectos humanos más "holísticos", como puede ser la emoción, pretende colocar la "verdad" de la relación entre sujetos y objetos en la experiencia emocional, proponiendo soluciones de diseño que vayan dirigidas a las emociones de los usuarios. El acercamiento de manera orgánica del individuo auténtico y la vida comunitaria, emerge como una de las soluciones propuestas de la disciplina del diseño a los mencionados problemas de la cultura del consumo moderna. Las modalidades sensoriales, junto a las relaciones cognitivas que se establecen con las emociones en nuestra vida diaria, se suman a las representaciones audiovisuales (apariencia de movimiento), y las recreaciones de dispositivos con énfasis en las cualidades emocionales (apariencia de lo vivo), de lo afectivo, generan (enriquecimiento de) experiencias, que van construyendo realidad y hábitos.

La cautela que se plantea en este tipo de investigación tiene que ver con las cualidades de lo real y lo aparente; en el circuito de lo emocional y lo racional, como la paridad en la que la actividad humana pareciera desarrollarse, se desdibujan a veces los signos en sus significados, las apariencias sustituyen a las realidades, la representación de lo vivo adquiere cualidad de vital.

El ser subjetivo

La escisión dada por la racionalidad versus la emocionalidad se vincula con la concepción de una claridad conceptual dada por el orden sucesivo y la percepción universal de un concepto, y que se entiende como lo objetivo, aquello cuyo objeto es evidente, a la vista, perceptible. En cambio se sabe que las cualidades humanas, de un ser que vive en el lenguaje y cuyas emociones "tiñen" su mundo posible y, por tanto, la cultura en la que vive, lo conducen a comprender que lo subjetivo forma parte activa del pensamiento. Y en el diseño, el pensamiento creativo. (Ricard, 2000)Entre estas dualidades se debate el diseño, pues lo objetivo como vecino de lo argumental, racional, comparte lugar con lo subjetivo, a decir de Buchanan: I diseño es en parte racional y cognitivo, en parte irracional, emotivo, intuitivo y no cognitivo. Es racional en la medida que hay comprensión consciente de las leyes de la naturaleza; es irracional en la medida en que las ciencias aún no hayan conseguido la revelación de las leyes de los fenómenos complejos. (...) Hay propiedades de los materiales y las formas que poseen atractivo estético y espiritual y que ninguna explicación científica parece posible explicar. Sin embargo, esto no es una confirmación de la existencia de un reino trascendental, ya que lo espiritual es considerado simplemente como un estado emocional complejo de la mente.9La emoción, que determinaría lo subjetivo del pensamiento, que se adhiere a las modalidades sensoriales, de movimiento y afecto físico, determina cualidades al quehacer del diseño, y a su pensamiento dentro de la cultura.

La determinación racionalista, en la que se ha de reducir los elementos a expresiones mínimas, factibles de cuantificar o bien medir, de modo de poder incluir en la dinámica económica o comercial, ha llevado a acentuar la inclinación propia de la razón para el control de, no sólo el proceso, sino también de los objetos, los artefactos, cosas, que se perciben y viven las afecciones de las interacciones con las personas. 
Desde otra vereda, y con una visión que ha pasado por las escuelas gestálticas, en las que se vuelve a unir aquello que por partes pierde sentido:El dualismo moderno separa pensamiento (i.e. sujeto) y objetos, porque una cosa son las representaciones mentales internas y otra la mesa y la silla y la taza de café. Sin embargo, nadie piensa pensamientos sino que piensa cosas; y si se piensan cosas, eso no puede hacerse solamente con el cerebro, sino también con los ojos, los oídos, la piel, etc.; esto puede notarse cuando uno se distrae, y el pensamiento queda ocupado por la mesa y la silla y la taza de café que tiene enfrente. El pensamiento, en efecto, siempre está en continuidad con los objetos físicos e inmateriales que pululan por la sociedad y la cultura. Objetos y pensamientos constituyen una unidad: uno sin el otro son un par de tonterías10.En esa unidad en la que objetos y pensamientos se conjugan, la idea racionalista resuelve separar las partes, para nombrarlas y para, de ese modo, hacerlas parte de una percepción dominada, invariable y atemporal.En rigor, los nombres son los límites reconocidos de los objetos, y a pesar de la pretensión cientificista de hacer lenguajes que limiten tajantemente los objetos, tales como el lenguaje matemático o las definiciones operacionales o la terminología técnica, la mayoría de los objetos comportan una cantidad de material que escapa a su nombre o a su representación, un quantum de indeterminación por lo cual, los límites se vuelven en realidad difuso. (...) Todo el matiz emocional de un discurso, por ejemplo, que no está contenido en el mensaje y no es verificable, sino que se hace presente en las pausas, los gestos, el tono, los silencios, en este halo, donde puede decirse que las imágenes son afectivas. La afectividad es una imagen no limitada por el nombre del objeto11.La cultura occidental, mediante la fuerte influencia de la ciencia permite entender la 'objetivación' (Maturana, 1992) como un acto en el que se racionaliza algo para convertirlo en un objeto; esta acción -propia de la inteligencia humana- provoca el pensamiento de aislar la actividad misma de pensar como si estuviera 'fuera' del cuerpo y pudiera 'estar desafectada' de otra cosa que no sea el objeto mismo.

No obstante, la posibilidad del pensamiento resulta imposible de desarrollarse sin el sustrato emocional, la percepción de un objeto sucede en el pensamiento 'afectado' de todos los aspectos que involucran las emociones:

El 'asombro y veneración' que provoca el pensamiento afectado de emociones frente al objeto como afirma Sennet (Sennet, 2009), permite sostener que el proceso de creación y dominio del diseño, del pensamiento en la actividad proyectual, involucra necesariamente los aspectos denominados subjetivos, inasibles y afectados del 'objeto' pensado:

"Sentir es pertenecer a la cosa sentida; esto se ejemplifica bien en el caso de las evocaciones de recuerdos, que se evocan con el único fin de pertenecer a ellos"12.

\section{Nombrando la forma}

La imagen en movimiento, así como el dispositivo que "exhibe" las imágenes son objetos de nuestra cotidianidad, que pueden ser vinculados a los aspectos emocionales de las personas desde el diseño, a través de la observación de las experiencias que en nuestra vida diaria tenemos con ellos.

La comprensión de las emociones pueden entenderse desde las representación de las formas (Fernández, 1994) a través una mirada relacionada a la gestalten. Es decir, la emoción estaría contenida en el movimiento mismo de la imagen, en la secuencia recreada en las formas, en las sugerencias de esas formas, en los giros lingüísticos, en los silencios, etc. 
El diseño apela a la investigación de la experiencia emocional producida por los productos, un reconocimiento, y autoconocimiento que se articula en el lenguaje. Se debe nombra aquello investigado, el hallazgo. El lenguaje se sitúa en la comunicación en un sustrato cognitivo, que podría diferenciarse de la emoción en la medida que las emociones operan en todo el estar humano, con la complejidad que ello conlleva.

La relación íntima entre lenguaje y emoción forma parte del proceso de razonamiento para la comunicación que va acompañado de la experiencia sensorial y la memoria emotiva. Solemos pensar en palabras y son éstas las que configuran cuerpos de significado para la relación humana y la comunicación cultural.

La visión holística del lenguaje, en el que se da una visión estructural de los fenómenos apela a una visión sincrónica en la que se maneja la relación de los elementos en su conjunto, configurándose una interrelación simultánea y pluridireccional de los elementos lingüísticos.

Este "vivir" en el lenguaje configura las dinámicas de significado en lo psicológico y, por ende, lo social; que presenta un problemática a la hora de objetivizar sus componentes para la observación (Maturana, 2004). Lakoff y Johnson13 nos advierten de los mitos existentes en la configuración del uso del lenguaje en su estudio sobre las metáforas "de la vida cotidiana". Plantean como el objetivismo se ha conformado como una idea de ser racional y por su contraparte, el subjetivismo forma parte de lo irracional o el "dejarse llevar por las emociones".

En una cultura que ha visto predominar las ideas de "ciencia, verdad, racionalidad, la precisión, la justicia y la imparcialidad", también se ha sujeto al mito del subjetivismo asociado a "las emociones, la intuición, la imaginación, la humanidad, el arte y una verdad más elevada". Esto provocaría temor a la metáfora, que es parte importante en la que se basa el lenguaje humano, por su imprecisión, al subjetivismo, que es un temor a lo que la emoción -y la imaginación- representan para la comprensión de las construcciones de significado.

La preocupación de los autores radica precisamente en que la metáfora uniría la razón y la imaginación, lo que denominan como "pensamiento metafórico" (comprendemos aquí ésta como la adquisición de imagen mediante los sentidos, quizás en un sentido más aristotélico y adjunto a la idea de memoria emotiva). Este pensamiento metafórico estaría indicando la racionalidad imaginativa del ser humano.

La adquisición de "verdad" (como parte de la incertidumbre que puede provocar el fenómeno perceptual visto desde la subjetividad), estaría siendo relativo al sistema conceptual de las personas, basado en las experiencias propias y las que se comparten con los demás dentro de una cultura. En esa prueba constante de "verdad", objetivismo y subjetivismo no se ajustarían a la comprensión del mundo, mediante las interacciones con él:El objetivismo se equivoca en el hecho de que entender, y la verdad en consecuencia, es algo necesariamente relativo a nuestro sistema conceptual absoluto o neutral. El objetivismo también olvida el hecho de que los sistemas conceptuales humanos son de naturaleza metafórica e implican una comprensión imaginativa de un tipo de cosas en términos de otro. El subjetivismo, por su parte, niega específicamente que nuestra comprensión, incluso nuestra comprensión más imaginativa se dé en términos de un sistema conceptual que está fundamentado en nuestro funcionamiento dentro de nuestro ambiente físico y cultural. También olvida el hecho de que la comprensión metafórica supone implicaciones metafóricas, que son una forma imaginativa de la racionalidad14.No se puede excluir dentro de la "experiencia física directa" el hecho de que el ser humano tenga una configuración específica (lo que en cierto modo condiciona casi toda su producción). Es posible de reconocer una diferenciación entre la dinámica física y espacial, que interactúa con la emocional, pero de la que 
no sustraemos una estructura conceptual definida. Nombrar las emociones mediante la palabra no alcanza para objetivizar un componente psicobiológico tan difícil de asir (Fernández, 1994); desde esa perspectiva, la palabra diaria, aquella que se dice sin pensar, parte del lenguaje cotidiano está mucho más cercano a la afectividad.

En esta línea, el movimiento aparente, la multiplicidad e imágenes, su sincronía, ruido, etc., bien podrían estar "diciendo" de las cualidades emocionales de nuestra sociedad.

La imposibilidad de poder contener el significado de las emociones en el lenguaje, inevitablemente conduce a otras manifestaciones del género humano. Es por tanto la forma una de las maneras de representar las emociones. Desde la forma aparece contenida una experiencia reflejo de nuestras experiencias vívidas, en las que la forma encarna aquella manifestación. La imagen en movimiento, recrea desde la forma lo más parecido a nuestra percepción de la realidad conocida. Lo vívido se mueve. No obstante, para los efectos de comunicar, y dado que el lenguaje no resulta del todo efectivo, la forma se traslada al lenguaje, en forma de metáfora. Desde esa perspectiva, el mundo se hace representable emocionalmente desde la forma y el tropo.

El diseño se plantea la búsqueda del equilibrio en la forma, de la relación de armonía entre las afecciones que percibe el ser humano y su entorno, resolviendo una interacción con base emocional, en la que el lenguaje de la metáfora es posible de representar la 'forma', la materialidad de la energía emocional.

En general, las formas tienen la facultad de hablar por las personas, no a través de las palabras, sino a través de la encarnación de las intenciones del que las crea y observa. Teniendo la habilidad ver de las cosas objetiva y subjetivamente al mismo tiempo, lo percibido en apariencia real y el perceptor como ser emocional y racional.

La apariencia de lo vívido

La concepción de emoción, como característica biológica fundamental del ser humano, se articula junto a los complejos procesos de vida y pensamiento; se proyecta (en el acto del ser humano como individuo) y refleja (en el acto del ser humano como ser social) en el ámbito de la cultura, y 'aparece' nombrando la cualidad 'vital' del hombre. Esta cualidad del ser humano emocional complementa la visión del ser racional, otorgándole características asociadas a la naturaleza, los ciclos vitales y el movimiento.

A riesgo de que no solo los productos son diseñados para demostrar gran apariencia emocional sino también el consumidor moderno esté poco a poco diseñado como un ser emocional, la relación afectiva de las personas con los objetos, y los contenidos audiovisuales de los objetos muestran cómo el ser humano ve proyectada su propia naturaleza, otorgando cualidades de lo vívido al movimiento aparente, transformando con ello su convivir urbano, su experiencia cotidiana y en la búsqueda de identidad.

Esta experiencia nutre al diseño de campo de investigación para ampliar el conocimiento de la cultura, las culturas; el reconocimiento de su propia responsabilidad frente a la creación de formas en el diseño en sus diferentes facetas. Como seres vivos conscientes, nos "movemos" en un entorno dinámico, las cualidades humanas se reflejan y proyectan en las representaciones de imágenes. Emoción y pensamiento que se presentan a través de las formas que podemos percibir y significar.

Notas 
1. 'Visión, sonido y movimiento' en su traducción al castellano.

2. Nos resulta interesante al análisis realizado a audiovisuales animados chilenos, en el que se da cuenta de cómo existe una narrativa que, en su mayor parte, se estructura de manera "conservadora y replicante de los cánones aristotélicos (...) centralista", lo que da cuenta de la visión de identidad que éstos aportan a la cultura local de un territorio específico. En Silva, Felipe. (2012). Revisión crítica de los audiovisuales animados chilenos. Revista Comunicación, nº 10, vol. 1. Pp. 599-605.

3. Press, Mike; Cooper, Rachel. (2009). El diseño como experiencia. El papel del diseño y los diseñadores en el siglo XXI. Barcelona: Gustavo Gili. P. 83.

4. Desmet, Pieter M.A.; van Erp, Jeroen; Karlsson, MariAnne. Ed. (2008). Design \& Emotion Moves. Cambridge: Cambridge Scholar Publishing.

5. El autor lo denomina appraisal.

6. Adank, Rodney; Warell, Anders. (2008). "FiveSensesTesting". Assessing and PredictingSensoryExperience of ProductDesign. En Desmet, Pieter; van Erp (eds.), Jeroen; Karlsson, MariAnne. Design\&Emotion Moves.Cambridge: Cambridge Scholars Publishing. Pp. 35-58.

7. Pelta, Raquel. (2014). Diseñar hoy. Temas contemporáneos de diseño gráfico. $7^{a}$ Ed. Barcelona: Paidós. P. 74.

8. Groys, Boris. (2008). Bajo sospecha. Una fenomenología de los medios. Valencia: Pre-Textos.

9. Buchanan, Richard; Margolin, Victor; eds. (1995). Discovering design. Explorations in designstudies. Chicago: The University of Chicago Press. P. 50.

10. Fernández Christlieb, Pablo. (1994). Teorías de las emociones y teoría de la afectividad. México: Iztapalapa 35. Extraordinario de 1994. Pp 89-112.

11. Ibídem.

12. Sennet, Richard. (2009). El artesano. Barcelona: Anagrama. P. 25.

13. Lakoff, George; Johnson, Mark. (1980). Metáforas de la vida cotidiana. Madrid; Cátedra.

14. Ibídem. P. 237.

Referencias bibliográficas

Desmet, P. M. A.; van Erp, J. \& Karlsson, M.A. Eds. (2008).Design \& Emotion Moves. Cambridge: Cambridge Scholar Publishing.

Buchanan, R.; Margolin, V.; eds. (1995). Discovering design. Explorations in designstudies. Chicago: The University of Chicago Press. 
Fernández Christlieb, P. (1994). Teorías de las emociones y teoría de la afectividad colectiva. Revista Iztapalapa 35, Nºxtraordinario de 1994, Pp. 89-112.

Groys, B. (2008). Bajo sospecha. Una fenomenología de los medios. Valencia: Pre-Textos.

Jordan, P. W. (2002). Designing Pleasurable Products: An Introduction to the New Human Factors. Londres:

Taylor \& Francis. Lakoff, G.; Johnson, M. (1980). Metáforas de la vida cotidiana. Madrid: Cátedra.

Maturana R., H. (1992). La objetividad: Un argumento para obligar. $3^{a}$ edición. Santiago: Lom.

Maturana R., H.; Pörksen, B. (2004). Del ser al hacer: Los orígenes de la biología del conocer. $2^{\mathrm{a}}$ edición. Santiago: Lom. Norman A., D. (2005). El diseño emocional. Por qué nos gustan (o no) los objetos cotidianos. Buenos Aires: Paidós.

Pelta, R. (2014). Diseñar hoy. Temas contemporáneos de diseño gráfico. $7^{a}$ Ed. Barcelona: Paidós.Press, M.; Cooper, R. (2009). El diseño como experiencia. El papel del diseño y los diseñadores en el siglo XXI. Barcelona: Gustavo Gili.

Ricard, A. (2000). La aventura creativa. Las raíces del diseño. Barcelona: Ariel.

Roberts, K. (2006). Sisomo-El futuro en pantalla. Creación de conexiones emocionales con el mercado con 'sight, sound and motion'. Barcelona: Urano.

Sennet, R. (2009). El artesano. Barcelona: Anagrama.

Silva M., F. (2012). Revisión crítica de los audiovisuales animados chilenos. Revista Comunicación, n 10, vol. 1. Pp. 599-605.

Abstract:

This paper deals with aspects of the emotional experience that different audiovisual designs generate based on different stimuli.

Key words: devices - screens - emotion.

Resumo:

Este escrito aborda os aspetos que fazem á experiência emocional que os diferentes designs audiovisuais geram baseados em diferentes estímulos.

Palavras chave: dispositivos - telas - emoção.

Ver y sentir (pantallas). Diseño, dispositivos y emoción fue publicado de la página 113 a página122 en Cuadernos del Centro de Estudios de Diseño y Comunicación № 66 